ARTICLE

Received 19 May 2015 | Accepted 27 Oct 2016 | Published 14 Dec 2016

DOI: $10.1038 /$ ncomms13717

OPEN

\title{
Evaluating the convergence between eddy-covariance and biometric methods for assessing carbon budgets of forests
}

\author{
M. Campioli ${ }^{1}$, Y. Malhi ${ }^{2, \star}$, S. Vicca ${ }^{1, \star}$, S. Luyssaert ${ }^{3, \star, \dagger}$, D. Papale ${ }^{4,5}$, J. Peñuelas ${ }^{6,7}$, M. Reichstein ${ }^{8}$, \\ M. Migliavacca ${ }^{8}$, M.A. Arain ${ }^{9} \&$ I.A. Janssens ${ }^{1}$
}

The eddy-covariance (EC) micro-meteorological technique and the ecology-based biometric methods (BM) are the primary methodologies to quantify $\mathrm{CO}_{2}$ exchange between terrestrial ecosystems and the atmosphere (net ecosystem production, NEP) and its two components, ecosystem respiration and gross primary production. Here we show that EC and BM provide different estimates of NEP, but comparable ecosystem respiration and gross primary production for forest ecosystems globally. Discrepancies between methods are not related to environmental or stand variables, but are consistently more pronounced for boreal forests where carbon fluxes are smaller. BM estimates are prone to underestimation of net primary production and overestimation of leaf respiration. EC biases are not apparent across sites, suggesting the effectiveness of standard post-processing procedures. Our results increase confidence in EC, show in which conditions EC and BM estimates can be integrated, and which methodological aspects can improve the convergence between EC and BM.

\footnotetext{
${ }^{1}$ Centre of Excellence PLECO (Plant and Vegetation Ecology), Department of Biology, University of Antwerp, 2610 Wilrijk, Belgium. ${ }^{2}$ Environmental Change Institute, School of Geography and the Environment, University of Oxford, Oxford OX1 3QY, UK. ${ }^{3}$ LSCE CEA-CNRS-UVSQ, Orme des Merisiers, F-91191 Gif-sur-Yvette, France. ${ }^{4}$ DIBAF, University of Tuscia, 01100 Viterbo, Italy. ${ }^{5}$ Euro-Mediterranean Center on Climate Change, CMCC, 73100 Lecce, Italy. ${ }^{6}$ CSIC, Global Ecology Unit, CREAF-CEAB-CSIC-UAB, Cerdanyola del Vallès, 08193 Barcelona, Catalonia, Spain. ${ }^{7}$ CREAF, Cerdanyola del Vallès, 08193 Barcelona, Catalonia, Spain. ${ }^{8}$ Max Planck Institute for Biogeochemistry, 07745 Jena, Germany. ${ }^{9}$ School of Geography \& Earth Sciences, McMaster University, Hamilton, Ontario, Canada L8S 4K1. * These authors contributed equally to this work. † Present address: Department of Ecological Science, VU University Amsterdam, 1081 HV Amsterdam, The Netherlands. Correspondence and requests for materials should be addressed to M.C. (email: matteo.campioli@uantwerpen.be).
} 
$\mathrm{T}$ he exchange of carbon dioxide $\left(\mathrm{CO}_{2}\right)$ between terrestrial ecosystems and the atmosphere is one of the major interactions between the biosphere and the atmosphere (Fig. 1), a key descriptor of ecosystem functioning and a major influence on atmospheric $\mathrm{CO}_{2}$ concentration. Two empirical approaches are generally used to quantify ecosystem $\mathrm{CO}_{2}$ exchange at the ecosystem level: the eddy-covariance technique (EC) and biometric methods (BM).

The EC technique features sound underlying micrometeorological principles, continuous monitoring, little perturbation or damaging of the system sampled and a sampling area (footprint) well suited for the scale of ecosystem-level estimates (Table 1). The long time series with high temporal resolution generated by EC can give detailed insights into the interactions between $\mathrm{CO}_{2}$ fluxes and synoptic and seasonal variability. Therefore, EC is very attractive for long-term monitoring of the net ecosystem-atmosphere $\mathrm{CO}_{2}$ exchange ${ }^{1}$ (or net ecosystem production $^{2}, \mathrm{NEP}$ ) and for the elucidation of its temporal changes and environmental controls. These properties have made EC the dominant methodology for estimating net and bulk fluxes of $\mathrm{CO}_{2}$ exchange ${ }^{1,3,4}$ and the standard method in a number of long-term and large-scale research infrastructures (for example, ICOS, NEON, AmeriFlux, TERN). However, as with every experimental method, EC has some drawbacks (Table 1), three of which are of particular importance. First, advective and low-frequency flows of $\mathrm{CO}_{2}$ are difficult to capture and can potentially lead to underestimation of fluxes during periods with low air turbulence,

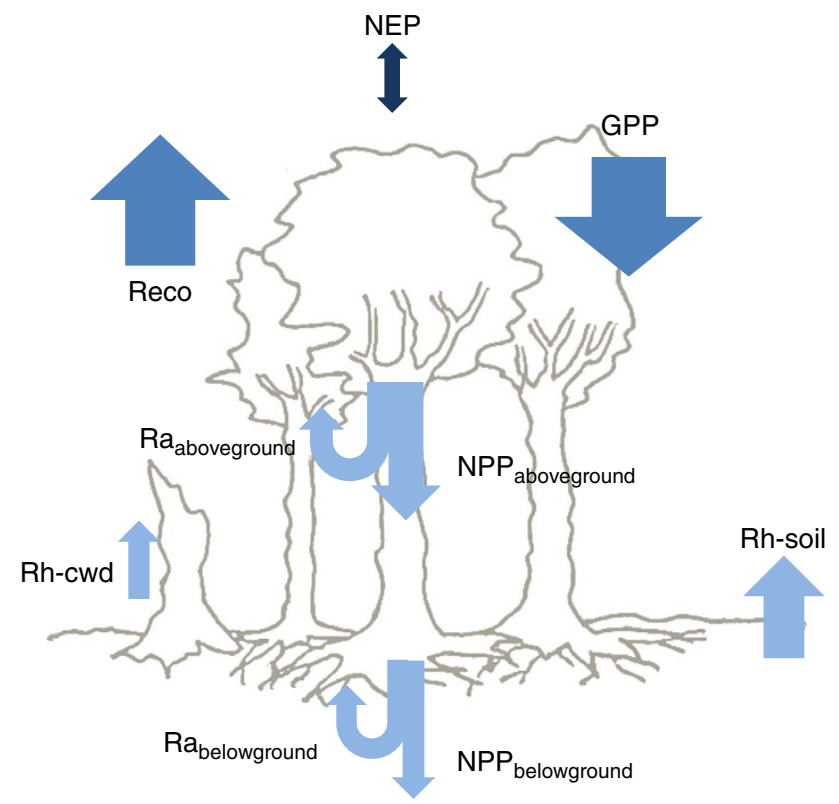

Figure 1 | Schematic representation of the major components of the forest carbon cycle. $\mathrm{Ra}_{\text {aboveground }}$ and $\mathrm{Ra}_{\text {belowground: }}$ above- and belowground autotrophic respiration, respectively (their sum is indicated as $\mathrm{Ra}$ ); Rh-soil and Rh-cwd: heterotrophic respiration from soil and coarse woody debris, respectively (their sum is indicated as $\mathrm{Rh}$ ); $\mathrm{NPP}_{\text {aboveground }}$ and $\mathrm{NPP}_{\text {belowground: }}$ above- and belowground net primary production, respectively (their sum is indicated as NPP); Reco: ecosystem respiration $(R e c o=R a+R h) ; G P P$ : gross primary production $(G P P=N P P+R a)$, and NEP: net ecosystem production (NEP $=\mathrm{GPP}-\mathrm{Reco}=\mathrm{NPP}-\mathrm{Rh})$. Each flux is associated with an arrow. Arrows pointing down indicate carbon (C) uptake, arrows pointing up indicate $C$ release, whereas the up-down arrow indicates that both $C$ release and $C$ uptake can occur. The dark blue arrow indicates NEP, the mid-blue arrows indicate the primary components of NEP (Reco and GPP), whereas the light blue arrows indicate the components of Reco and GPP. typically ecosystem respiration at night ${ }^{5}$. This drawback is particularly important in the presence of variable topography, favouring air drainage and breezes ${ }^{6}$, or thick canopy, hindering mixing of the air within and above it ${ }^{7,8}$. Second, EC has a persistent inability to close the surface energy budget, leading to fears that if energy fluxes are being underestimated, then $\mathrm{CO}_{2}$ fluxes may also be underestimated ${ }^{\mathrm{P}}$. Third, EC measures NEP directly, but its two main components, ecosystem photosynthetic $\mathrm{CO}_{2}$ uptake, or gross primary production (GPP), and ecosystem carbon (C) release, or ecosystem respiration (Reco) (Fig. 1), can only be estimated indirectly by post-processing the data of $\mathrm{CO}_{2}$ exchange ${ }^{9,10}$. In other words, EC relies on a single measurement to estimate net and bulk $\mathrm{CO}_{2}$ fluxes.

The BM approach uses a well-established but un-standardized set of techniques, such as plant growth assessment, chamberbased flux measurements and repeated stock inventories that allow a direct estimation of the component processes of the ecosystem C cycle (for example, net primary production (NPP), heterotrophic respiration $(\mathrm{Rh})$ and autotrophic respiration $(\mathrm{Ra})$; Fig. 1; Table 1) and changes in soil and biomass stock, from which NEP, Reco and GPP can be calculated. Advantages of this approach include insights into the internal $\mathrm{C}$ dynamics of an ecosystem, (for example, partitioning between $\mathrm{Ra}$ and $\mathrm{Rh}$, allocation of photosynthates between Ra and NPP and allocation of NPP between leaves, wood and fine roots), and applicability to almost any site (for example, small plots, sites with strong spatial heterogeneity, high canopy thickness or steep topography) and meteorological conditions (for example, periods with low air turbulence) without the requirements imposed by the EC technique. Typically, BM approaches are also very useful for evaluating the impact of environmental manipulative experiments on the C cycle ${ }^{11}$, whereas EC cannot be applied to experimental plots of limited size ${ }^{5}$. On the other hand, BM approaches also have drawbacks (Table 1). In particular, biometric measurements are typically performed on few replicated individuals and plant organs (for example, few leaves and branches) or small ecosystem plots that need to be up-scaled, assuming homogeneity within and among plants and in all relevant environmental variables (for example, soil moisture, nutrients, microclimate, soil type). Moreover, there is always the possibility that some potentially important components of the $\mathrm{C}$ budget have not been accounted for (for example, transfer of photosynthates to mycorrhizae production, ground flora productivity or loss to herbivory) and that some of the biometric techniques can disturb the portion of the ecosystem being sampled (for example, root measurements disturb the soil, stem respiration chambers can affect microclimate and pressure of the air space sampled). Finally, most biometric measurements cannot be easily monitored continuously, making the linkage between changes in fluxes to specific weather events more challenging.

As the advantages of BM (for example, applicability to most sites and environmental conditions) largely match the potential disadvantages of the EC technique (and vice versa) and the two techniques are fully independent, the comparison between EC and BM has been developed as the most suited way to corroborate both approaches ${ }^{12}$. NEP estimates obtained with $\mathrm{EC}$ and $\mathrm{BM}$ have been compared in a number of studies, but no clear picture has yet emerged. Agreement of multi-year NEP estimates between methods varied widely among sites, from very good ${ }^{13}$ to very poor ${ }^{14}$. A primary cause of our limited understanding of EC-BM convergence lies in the fact that existing empirical studies are based only on one or few sites (for example, five sites ${ }^{12}$ ) and very few studies have attempted quantitative multi-site syntheses ${ }^{15}$. In practice, this has made it difficult to pin-point the reasons behind the observed cases with low convergence because statistical analyses have not been 
Table 1 | Positive and negative characteristics of eddy-covariance and biometric methods.

\section{Characteristics of the technique}

Directness of approach 1,25

Temporal and spatial up-scaling ${ }^{1,18}$

Applicability to small-footprint studies

Interference with sampled system ${ }^{1}$

Sensitivity to low turbulence environment ${ }^{1,8,18}$

Impact of measuring set-up on microclimate $e^{1,53}$

Impact of complex terrain ${ }^{1}$

Compartment-level understanding and partitioning of fluxes and allocation ${ }^{16}$

Unaccounted/miscounted carbon fluxes at tree organ/ecosystem compartment level (e.g. understory fluxes, herbivory) ${ }^{16,54,55}$

Set-up costs 56

Ongoing labour requirements ${ }^{1}$

Technical capacity requirements for data collection and processing

EC

BM

Very positive $(++)$, positive $(+)$, negative $(-)$ or very negative $(--)$ characteristics of the eddy-covariance $(E C)$ and biometric (BM) methods used for the determination of net ecosystem production (NEP), ecosystem respiration (Reco) and gross primary production (GPP) of forest ecosystems.

${ }^{\star} \mathrm{NEP}$

$\nmid$ Reco and GPP.

Table 2 | Comparison of carbon fluxes obtained from eddy-covariance or biometric methods for forests worldwide and in the main climatic zones.

\begin{tabular}{|c|c|c|c|c|}
\hline & \multicolumn{3}{|c|}{ BM versus EC } & \multirow{2}{*}{$\begin{array}{c}\mathrm{BM}_{\Delta \mathrm{s}} \text { versus EC } \\
\text { NEP }\end{array}$} \\
\hline & NEP & Reco & GPP & \\
\hline \multicolumn{5}{|l|}{ Global } \\
\hline Site replicates $(n)$ & 31 & 25 & 18 & 7 \\
\hline Absolute difference (mean \pm s.e.m) & $-98 \pm 32$ & $120 \pm 61$ & $25 \pm 67$ & $32 \pm 87$ \\
\hline Significance difference $(P)$ & $0.0042^{\star \star}$ & $0.061^{+}$ & 0.71 & 0.73 \\
\hline Relative difference (mean \pm s.e.m in \%) & NA & $13 \pm 4$ & $5 \pm 4$ & NA \\
\hline \multicolumn{5}{|l|}{ Boreal } \\
\hline Site replicates $(n)$ & 6 & 6 & 4 & 1 \\
\hline Absolute difference (mean \pm s.e.m) & $-167 \pm 44$ & $189 \pm 75$ & $89 \pm 59$ & 26 \\
\hline Significance difference $(P)$ & $0.013^{\star}$ & $0.031^{\star}$ & 0.23 & NA \\
\hline Relative difference (mean \pm s.e.m in \%) & NA & $18 \pm 7$ & $8 \pm 5$ & NA \\
\hline \multicolumn{5}{|l|}{ Temperate } \\
\hline Site replicates $(n)$ & 22 & 15 & 11 & 6 \\
\hline Absolute difference (mean \pm s.e.m) & $-95 \pm 28$ & $160 \pm 85$ & $59 \pm 100$ & $33 \pm 102$ \\
\hline Significance difference $(P)$ & $0.0028^{\star \star}$ & $0.079^{+}$ & 0.57 & 0.76 \\
\hline Relative difference (mean \pm s.e.m in \%) & NA & $16 \pm 6$ & $6 \pm 6$ & NA \\
\hline \multicolumn{5}{|l|}{ Tropical } \\
\hline Site replicates $(n)$ & 3 & 4 & 3 & NA \\
\hline Absolute difference (mean \pm s.e.m) & $10 \pm 275$ & $-137 \pm 138$ & $-182 \pm 119$ & NA \\
\hline Significance difference $(P)$ & 1.0 & 0.39 & 0.26 & NA \\
\hline Relative difference (mean \pm s.e.m in \%) & NA & $-5 \pm 5$ & $-5 \pm 3$ & NA \\
\hline \multicolumn{5}{|c|}{$\begin{array}{l}\text { Statistics of the comparison of net ecosystem production (NEP), ecosystem respiration (Reco) and gross primary production (GPP) at global scale and for the boreal, temperate and tropical zones, } \\
\text { separately, assessed with eddy-covariance }(E C) \text { and two types of biometric methods: standard biometric methods based on measurements of production and respiration (BM) and biometric methods } \\
\text { based on consecutive inventories of ecosystem carbon stocks }(B M \Delta s) \text {. The difference between methods is expressed as Absolute difference (BM estimate }- \text { EC estimate) and Relative difference } \\
\text { (BM estimate }- \text { EC estimate)/((BM estimate }+ \text { EC estimate)/2). Difference at } 0.001<P<0.01,0.01<P<0.05 \text { and } 0.05<P<0.10 \text { are marked with }{ }^{\star *} \text {, }{ }^{*} \text { and }+ \text {, respectively. The notation } N A \\
\text { indicates data not available. }\end{array}$} \\
\hline
\end{tabular}

undertaken yet. Comparability of BM and EC estimates for Reco and GPP has been studied even less than for NEP. We are not aware of any multi-site synthesis efforts and existing comparisons are limited to 3-4 sites within the same region ${ }^{16,17}$. Lack of knowledge about EC and BM comparison for Reco and GPP complicates the analysis of NEP estimates obtained by the two approaches (for example, the two approaches could give similar NEP while diverging in their estimation of the two components). As a result of the multiple limitations on the corroboration of the empirical estimates of NEP, Reco and GPP, our understanding of the uncertainty of ecosystem $\mathrm{C}$ fluxes has stagnated for over a decade: the suspected biases of EC have not been clarified ${ }^{18}$ and the uncertainties in BM estimates remain underexplored.
Here we investigate the agreement between EC- and BM-based estimates of ecosystem $\mathrm{CO}_{2}$ fluxes by addressing three research questions: how do EC and BM-based fluxes compare across and within the boreal, temperate and tropical forest zones? Is any discrepancy between EC and BM flux estimates related to stand, environmental and methodological variables? Can the EC-BM comparison provide insights into long-standing suspected biases of the EC technique? The answers are provided by analyzing a novel EC and BM data set comprising annual estimates of NEP, Reco and GPP for 40 sites across five continents, spanning boreal, temperate and tropical forests. The convergence between EC and $\mathrm{BM}$ fluxes is analysed through the absolute and relative flux difference, globally and for the three climatic zones separately, 
and by testing the correlation of the flux differences with a large set of stand, environmental and methodological variables (for example, indices of topographical complexity, leaf are index, mean annual temperature, approaches to scale up the tree respiration). It is found that EC and BM provide globally comparable estimates of Reco and GPP but different NEP, which is smaller and more susceptible to biases. Moreover, biases of opposite direction are likely to cancel out when estimating Reco and GPP. Low convergence is associated with BM approaches underestimating NPP and neglecting light inhibition of leaf dark respiration, with discrepancies more pronounced for the boreal zone. Major EC biases are not apparent across sites, increasing our confidence in this technique.

\section{Results}

Data set of process components of ecosystem carbon cycle. Our uniform and quality-checked data set of BM and EC-based forest C fluxes comprised 31 sites with $\mathrm{BM}$-based NEP ( $\left.\mathrm{NEP}_{\mathrm{BM}}\right)$ and EC-based NEP $\left(\mathrm{NEP}_{\mathrm{EC}}\right), 25$ sites with BM-based Reco $\left(\mathrm{Reco}_{\mathrm{BM}}\right)$ and EC-based Reco $\left(\mathrm{Reco}_{\mathrm{EC}}\right)$ and 18 sites with BM estimates of GPP $\left(\mathrm{GPP}_{\mathrm{BM}}\right)$ and EC estimates of GPP $\left(\mathrm{GPP}_{\mathrm{EC}}\right)$ (Supplementary Tables 1-4; Supplementary Fig. 1; Supplementary Data 1). About $60-70 \%$ of the sites were in the temperate zone, $20-25 \%$ in the boreal zone and $10-15 \%$ in the tropical zone (Table 2). NEP ranged from -110 to $830 \mathrm{gC} \mathrm{m}^{-2} \mathrm{y}^{-1}$, Reco from 460 to $3,300 \mathrm{gC} \mathrm{m}^{-2} \mathrm{y}^{-1}$, and GPP from 600 to $3,600 \mathrm{gC} \mathrm{m}^{-2} \mathrm{y}^{-1}$ (EC data). Furthermore, BM data allowed insights into the different components of the $\mathrm{C}$ cycle of the studied forests. First, NPP ranged from 170 to $1,500 \mathrm{gC} \mathrm{m}^{-2} \mathrm{y}^{-1}$, Ra from 490 to $1,900 \mathrm{gC} \mathrm{m}^{-2} \mathrm{y}^{-1}$ whereas soil heterotrophic respiration ( $\mathrm{Rh}$ soil) from 170 to $1,400 \mathrm{gC} \mathrm{m}^{-2} \mathrm{y}^{-1}$. Second, leaves, aboveground wood and roots accounted on average for $30 \pm 2 \%$ (mean and s.e.m), $34 \pm 2 \%$ and $30 \pm 3 \%$ of NPP, respectively, and $39 \pm 4 \%, 22 \pm 3 \%$ and $38 \pm 4 \%$ of $\mathrm{Ra}$, respectively. Third, fine roots accounted for $70 \pm 7 \%$ of root NPP. Fourth, Reco was composed of $55 \pm 3 \%$ soil respiration (Rsoil), $28 \pm 2 \%$ leaf respiration (Rleaf), $15 \pm 2 \%$ aboveground wood respiration (Rwood) and $5 \pm 1 \%$ heterotrophic respiration of coarse woody debris (Rh-cwd), that is, $68 \pm 3 \%$ by Ra and $32 \pm 3 \%$ by Rh.

Net ecosystem production. $\mathrm{NEP}_{\mathrm{BM}}$ agreed with $\mathrm{NEP}_{\mathrm{EC}}$ along the range of flux measurements as indicated by the slope of the regression $\mathrm{NEP}_{\mathrm{BM}}$ versus $\mathrm{NEP}_{\mathrm{EC}}\left(1.06 ; \mathrm{CI}_{95 \%}=0.74-1.53\right.$, $R^{2}=0.54$ ) (Fig. 2a). However, $\mathrm{NEP}_{\mathrm{EC}}$ was significantly larger than $\mathrm{NEP}_{\mathrm{BM}}\left(P<0.01\right.$; mean difference $98 \pm 32 \mathrm{gCm}^{-2} \mathrm{y}^{-1}$; Table 2). This trend was caused by the extratropical sites, particularly in the boreal zone, where the mean difference was as large as $167 \pm 44 \mathrm{gC} \mathrm{m}^{-2} \mathrm{y}^{-1}$ (Table 2).

The difference between $\mathrm{NEP}_{\mathrm{EC}}$ and $\mathrm{NEP}_{\mathrm{BM}}$ was not correlated to the elevation variability, topographical slope and leaf area index (LAI), or to any of the other environmental and stand variables considered (Table 3). Similarly, the difference between $\mathrm{NEP}_{\mathrm{EC}}$ and $\mathrm{NEP}_{\mathrm{BM}}$ was not correlated to the type of $\mathrm{BM}$ approach applied (that is, different methods to measure fine root NPP, leaf NPP and Rh-soil, different quality of the allometric relationships used to estimate wood NPP and accounting or not for Rh-cwd; Table 3; Supplementary Fig. 2). Finally, the difference between $\mathrm{NEP}_{\mathrm{EC}}$ and $\mathrm{NEP}_{\mathrm{BM}-\Delta \mathrm{S}}$ (BM-based NEP derived from the difference in ecosystem $C$ stocks between two points in time, thus avoiding the use of NPP and Rh data, see Methods and Supplementary Table 5) was also not statistically significant (Table 2).

Ecosystem respiration. The regression between $\mathrm{Reco}_{\mathrm{BM}}$ and $\mathrm{Reco}_{\mathrm{EC}}$ had a slope of $0.86\left(\mathrm{CI}_{95 \%}=0.73-1.02 ; R^{2}=0.87\right)$
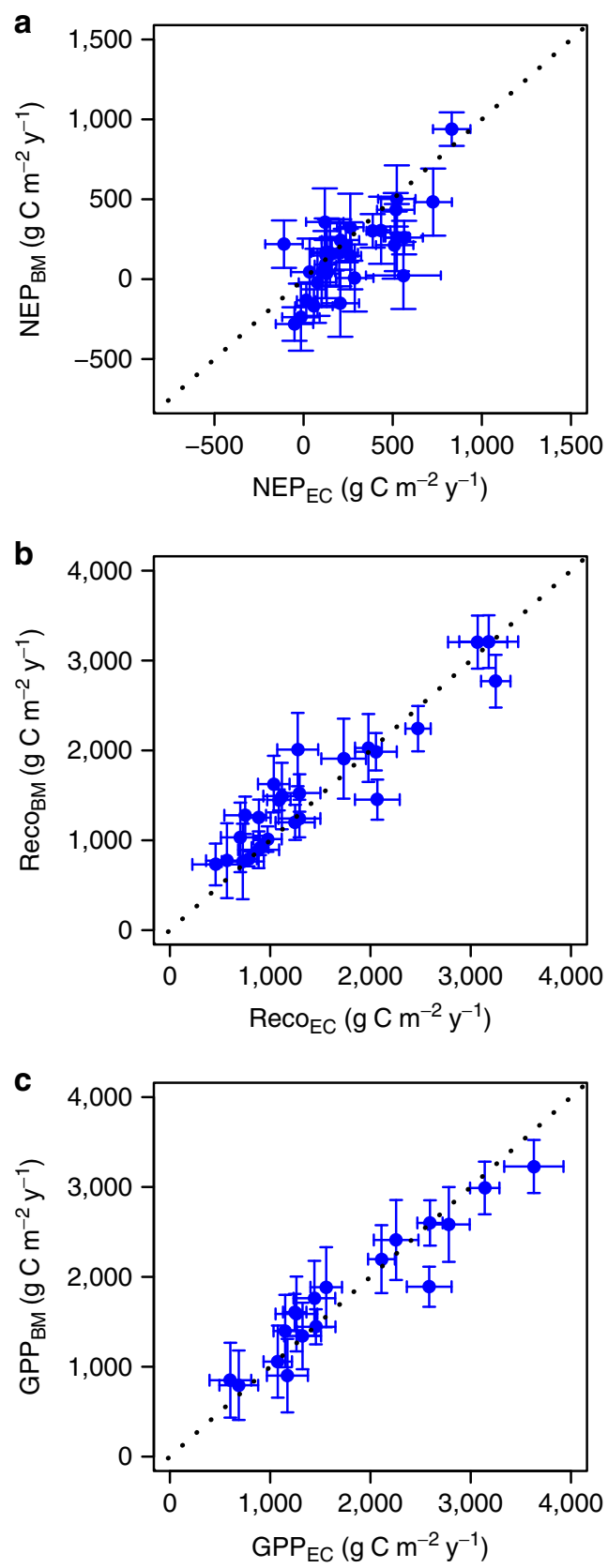

Figure 2 | Comparison of carbon fluxes obtained from eddy-covariance or biometric methods for worldwide forests. (a) Net ecosystem production (NEP, $n=31$ ), (b) ecosystem respiration (Reco, $n=25$ ) and (c) gross primary production (GPP, $n=18$ ) from eddy-covariance (EC; $x$ axis) and biometric (BM; $y$ axis) methods. Bars indicate confidence intervals which are derived from uncertainty ranges related to biome and latitude,

constrained by a reduction factor depending on the methodology and by the number of replicate years of measurement (see Methods). The dotted line is the 1:1 line.

(Fig. 2b). Reco $\mathrm{BM}_{\mathrm{B}}$ was on average $13 \pm 4 \%$ larger than $\mathrm{Reco}_{\mathrm{EC}}$ (marginally significant at $P=0.061$ ). Although the differences between EC- and BM-based estimates of Reco did not present any correlation with the indices of topographical complexity, LAI or any other environmental or stand variables (Table 3 ), $\mathrm{Reco}_{\mathrm{BM}}$ and $\mathrm{ReCO}_{\mathrm{EC}}$ were significantly different for the boreal forests (difference $18 \pm 7 \%, P=0.031$ ) but were not significantly different for the temperate $(16 \pm 6 \%, P=0.079)$ and tropical forests $(5 \pm 5 \%, P=0.39)$ (Table 2$)$. 
Table 3 | Relationship between the difference in forest carbon fluxes estimated from eddy-covariance and biometric methods and site or methodological characteristics.

\begin{tabular}{|c|c|c|c|c|c|c|c|}
\hline \multirow[t]{3}{*}{ Variables } & \multirow[t]{3}{*}{ Category (units) } & \multirow{2}{*}{\multicolumn{2}{|c|}{$\begin{array}{c}\text { NEP }_{\text {EC }^{-}} \\
\text {NEP }_{\mathbf{B M}} \\
\text { Difference }\end{array}$}} & \multirow{2}{*}{\multicolumn{2}{|c|}{$\begin{array}{c}\text { Reco }_{\mathrm{EC}}-\mathbf{R e c O}_{\mathrm{BM}} \\
\text { Relative } \\
\text { difference }\end{array}$}} & \multirow{2}{*}{\multicolumn{2}{|c|}{$\begin{array}{c}\text { GPP }_{\mathrm{EC}}-\mathrm{GPP}_{\mathrm{BM}} \\
\begin{array}{c}\text { Relative } \\
\text { difference }\end{array}\end{array}$}} \\
\hline & & & & & & & \\
\hline & & $\boldsymbol{P}$ & $R^{2}$ & $\boldsymbol{P}$ & $R^{2}$ & $\boldsymbol{P}$ & $R^{2}$ \\
\hline \multicolumn{8}{|l|}{ Topography, environmental and stand variables } \\
\hline Elevation variability & $\mathrm{m}$ & 0.89 & $<0.01$ & 0.82 & $<0.01$ & 0.13 & 0.13 \\
\hline Topographical slope & $\%$ & 0.80 & $<0.01$ & 0.42 & 0.03 & $0.086^{\dagger}$ & 0.17 \\
\hline Leaf area index & $m^{2} m^{-2}$ & 0.36 & 0.03 & 0.91 & $<0.01$ & 0.60 & 0.02 \\
\hline Leaf type & Needleleaved/broadleaved/mixed & 0.27 & 0.04 & 0.24 & 0.07 & 0.44 & 0.04 \\
\hline Leaf habit & Evergreen/deciduous/mixed & 0.47 & 0.02 & 0.32 & 0.06 & 0.11 & 0.16 \\
\hline Fertility & Low/medium/high & 0.28 & 0.05 & 0.61 & 0.01 & 0.57 & $0.07^{\dagger}$ \\
\hline Climate zone & Boreal/temperate/tropical & 0.16 & $0.07^{\dagger}$ & 0.12 & 0.15 & 0.34 & 0.08 \\
\hline Mean annual precipitation & $\mathrm{mm}$ per year & 0.31 & $0.02^{\dagger}$ & 0.25 & 0.06 & 0.34 & 0.06 \\
\hline Mean annual temperature & ${ }^{\circ} \mathrm{C}$ & 0.42 & $0.05^{\dagger}$ & 0.13 & 0.10 & 0.22 & 0.09 \\
\hline \multicolumn{8}{|l|}{ Methodological variants } \\
\hline Methods to measure fine root NPP & $\begin{array}{l}\text { Sequential coring/ingrowth cores/ } \\
\text { minirhizotron technique/other }\end{array}$ & 0.22 & 0.11 & NA & NA & 0.11 & 0.32 \\
\hline Allometric relationships to measure wood NPP & Low/moderate/high quality & 0.58 & 0.04 & NA & NA & 0.69 & 0.02 \\
\hline Method of measuring leaf NPP $\ddagger$ & leaf fall collection/allometry & 0.43 & 0.04 & NA & NA & 0.85 & $<0.01$ \\
\hline Chamber method to measure Rsoil & NSNF/NSF & NA & NA & $0.008^{\star \star}$ & 0.34 & NA & NA \\
\hline Scrubbing of $\mathrm{CO}_{2}$ before Rsoil measurement ${ }^{\S}$ & Yes/no & NA & NA & 0.22 & 0.09 & NA & NA \\
\hline Methods to measure Rh-soil & $\begin{array}{l}\text { Root exclusion/indirectly from estimation of } \\
\text { root respiration/component integration/other }\end{array}$ & 0.59 & 0.03 & NA & NA & NA & NA \\
\hline Consideration of Rh-cwd & Yes/no & 0.16 & 0.07 & 0.84 & $<0.01$ & NA & NA \\
\hline $\begin{array}{l}\text { Variables of models for integration of Rsoil at } \\
\text { annual scale }\end{array}$ & Soil temperature/soil temperature and water & NA & NA & 0.16 & 0.10 & NA & NA \\
\hline $\begin{array}{l}\text { Variables of models for integration of Rleaf at } \\
\text { annual scale }\end{array}$ & $\begin{array}{l}\text { Temperature/temperature in combination with } \\
\text { other }\end{array}$ & NA & NA & 0.13 & 0.11 & 0.32 & 0.07 \\
\hline $\begin{array}{l}\text { Parameterization of models for integration of } \\
\text { Rleaf at annual scale }\end{array}$ & Site-specific/generic & NA & NA & $0.043^{\star}$ & 0.17 & 0.40 & 0.04 \\
\hline $\begin{array}{l}\text { Variability of temperature sensitivity of Rleaf in } \\
\text { models for integration of Rleaf at annual scale }\end{array}$ & Yes/no & NA & NA & 0.23 & 0.06 & 0.65 & 0.013 \\
\hline $\begin{array}{l}\text { Consideration of light inhibition of leaf dark } \\
\text { respiration in Rleaf }\end{array}$ & Yes/no & NA & NA & $0.041^{\star}$ & 0.17 & 0.43 & 0.04 \\
\hline $\begin{array}{l}\text { Consideration of leaf growth respiration in } \\
\text { Rleaf }\end{array}$ & Yes/no & NA & NA & 0.94 & $<0.01$ & 0.64 & 0.14 \\
\hline $\begin{array}{l}\text { Consideration of wood growth respiration in } \\
\text { Rwood }\end{array}$ & Yes/no & NA & NA & 0.34 & 0.039 & 0.54 & 0.024 \\
\hline $\begin{array}{l}\text { Variables of models for integration of Rwood at } \\
\text { annual scale }\end{array}$ & $\begin{array}{l}\text { Temperature/temperature in combination with } \\
\text { other }\end{array}$ & NA & NA & 0.25 & 0.07 & $0.086^{\dagger}$ & 0.21 \\
\hline Variable used to scale up Rwood at stand level & Wood volume/wood area & NA & NA & 0.37 & 0.04 & 0.44 & 0.04 \\
\hline $\begin{array}{l}\text { Separation contribution of branch and stem in } \\
\text { Rwood }\end{array}$ & Yes/no & NA & NA & 0.68 & $<0.01$ & 0.42 & 0.04 \\
\hline \multicolumn{8}{|c|}{ 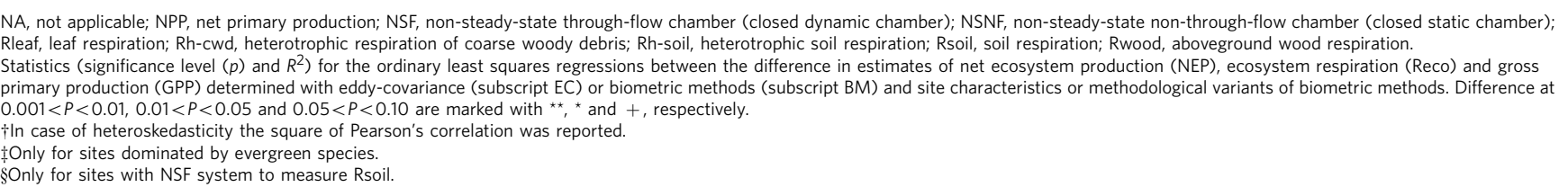 } \\
\hline
\end{tabular}

The degree of the convergence between Reco $_{\mathrm{BM}}$ and $\mathrm{Reco}_{\mathrm{EC}}$ differed according to the type of chamber technique used to measure Rsoil. For sites where closed static chambers or nonsteady-state non-through-flow chambers (NSNF) were used, Reco $_{\mathrm{BM}}$ and $\mathrm{Reco}_{\mathrm{EC}}$ did not differ significantly $(P=0.36$; Fig. 3a). On the other hand, the use of closed dynamic chambers or non-steady-state through-flow chamber (NSF) resulted in Reco $_{\mathrm{BM}}$ significantly larger than $\operatorname{Reco}_{\mathrm{EC}}(20 \%, P<0.001$; Fig. $3 a)$. Within the NSF group, the low level of convergence between Reco $_{\mathrm{BM}}$ and $\mathrm{Reco}_{\mathrm{EC}}$ did not differ $(P=0.22)$ when standard systems and systems prescribing scrubbing of $\mathrm{CO}_{2}$ before the flux measurements (for example, Li-Cor LI-6400-09 system; LI-COR Biosciences, Lincoln, USA) were compared (Table 3). Also the
BM approach used for measuring Rleaf had an impact on the convergence between $\mathrm{Reco}_{\mathrm{BM}}$ and Reco $\mathrm{EC}$. Neglecting light inhibition of leaf dark respiration increased the difference between methods by about 20\% ( $P=0.041$; Fig. 3b; Table 3$)$. Likewise, models used to scale up point measurements of Rleaf to annual values also increased the difference between methods by about $20 \%$ when they had a generic formulation that is, without a site-specific parameterization $(P=0.043$; Fig. 3c; Table 3$)$. The different chamber systems for measuring Rsoil affected the convergence between $\mathrm{Reco}_{\mathrm{BM}}$ and $\mathrm{Reco}_{\mathrm{EC}}$ also when their effect was disentangled from the effect of light inhibition and parametrization type of leaf respiration (Supplementary Fig. 3). On the other hand, the effect of neglecting light inhibition was 
a

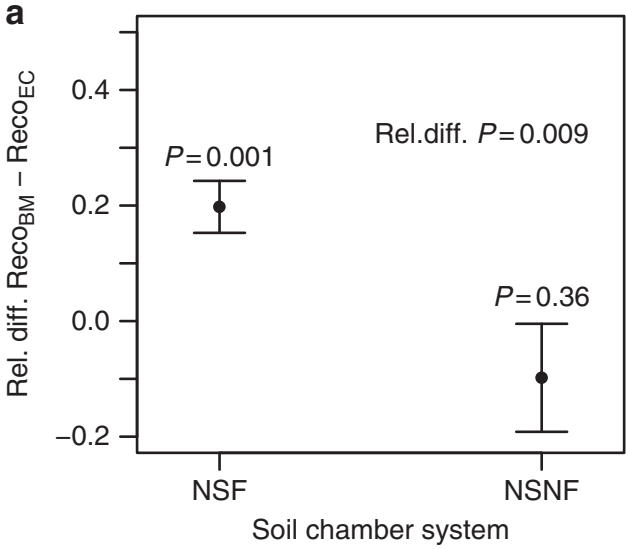

b

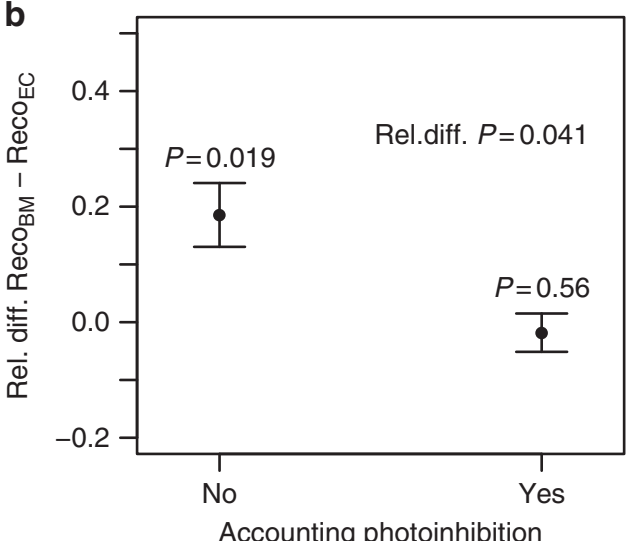

C



Figure 3 | Impact of variants of biometric methods on the difference between ecosystem respiration from biometric methods and eddy-covariance. The relative difference between ecosystem respiration from biometric methods $\left(\operatorname{RecO}_{B M}\right)$ and eddy-covariance (RecO $\mathrm{EC}_{\mathrm{EC}}$ ) $\left[\left(\operatorname{RecO}_{B M}-\operatorname{RecO}_{E C}\right) /\left(\left(\operatorname{RecO}_{E C}+\operatorname{RecO}_{B M}\right) / 2\right)\right]$ when (a) using different chamber systems to measure soil respiration (NSF: non-steady-state through-flow chamber; NSNF: non-steady-state non-through-flow chambers), (b) whether light inhibition is accounted for when estimating leaf respiration (Rleaf), and (c) employing generic or site-specific parameterization for the empirical models used to scale up the point measurements of Rleaf to the annual scale. Points indicate means and bars the standard error of the mean. The $P$ value above each point indicates the significance level of the difference between $\mathrm{ReCO}_{\mathrm{BM}}$ and $\mathrm{ReCO} \mathrm{EC}_{\mathrm{EC}}$ for each case, whereas the significance level $P$ of each factor (that is, chamber system, accounting light inhibition, parameterization type) is indicated as rel. diff. $P$ (relative difference between Reco $_{B M}$ and $\operatorname{RecO}_{E C}$ ) and is reported in the top right of each panel. stronger than the parameterization type as it was the only one significant when the two effects were disentangled. In fact, a two-way analysis of variance (ANOVA) accounting for Rleaf light inhibition (yes/no) and parametrization type (site-specific/ generic), performed only for sites with NSF measurements, showed that only light inhibition was significant $(P=0.035$; parametrization type: $P=0.23$; interaction term: $P=0.70)$.

No impact was observed on the convergence between Reco $_{\mathrm{BM}}$ and $\mathrm{ReCO}_{\mathrm{EC}}$ from other technical variants in measuring Reco $\mathrm{BM}_{\mathrm{B}}$. The latter included: considering (or neglecting) Rh-cwd and the growth respiration of Rleaf and Rwood; the differentiation of Rwood in stem and branch respiration; the types of model drivers (temperature or others) used for the annual estimation of Rleaf, Rwood and Rsoil; the variability of the temperature sensitivity of models of Rleaf, and the type of upscaling variable used for Rwood (wood volume or wood area) (Table 3). Similarly, the partitioning method used to derive $\mathrm{Reco}_{\mathrm{EC}}$ from $\mathrm{NEP}_{\mathrm{EC}}$ did not have a major impact on the difference between Reco $_{\mathrm{EC}}$ and $\mathrm{RecO}_{\mathrm{BM}}$. The use of the daytime derived Reco instead of night time derived Reco decreased the divergence between $\mathrm{Reco}_{\mathrm{EC}}$ and Reco $_{\mathrm{BM}}$ (from $13 \pm 7 \%$ to $9 \pm 4 \%$ ). However, this improvement was not statistically significant $(P=0.29)$ because daytime derived Reco $_{\mathrm{EC}}$ did not differ significantly from night time derived $\operatorname{Reco}_{\mathrm{EC}}\left(4 \pm 4 \%\right.$, daytime $\operatorname{Reco}_{\mathrm{EC}}>$ night time Reco $\left.\mathrm{EC} ; P=0.64\right)$.

Gross primary production. The regression of $\mathrm{GPP}_{\mathrm{BM}}$ versus $\mathrm{GPP}_{\mathrm{EC}}$ had a slope of $0.84\left(\mathrm{CI}_{95 \%}=0.70-0.99 ; R^{2}=0.90\right)$. The agreement between methods was confirmed by the small and non-significant relative difference between $\mathrm{GPP}_{\mathrm{BM}}$ and $\mathrm{GPP}_{\mathrm{EC}}$ $(5 \pm 4 \%)$. The mean difference between $\mathrm{GPP}_{\mathrm{BM}}$ and $\mathrm{GPP}_{\mathrm{EC}}$ was small (up to $8 \%$ ) and non-significant also when the analysis was performed for the three climatic zones separately (Table 2). As for NEP and Reco, the differences between EC- and BM-based estimates of GPP were not related to any environmental or stand variables (Table 3). The relationship between the $\mathrm{GPP}_{\mathrm{BM}}$ and $\mathrm{GPP}_{\mathrm{EC}}$ difference and the topographical slope was marginally significant, but this was due to one outlier (Supplementary Fig. 4; the relationship was not significant at $P=0.19$ when the outlier was removed) and was therefore considered irrelevant. The impact of different BM approaches to measure NPP, Rleaf and Rwood did not have any significant impact on the difference between $\mathrm{GPP}_{\mathrm{EC}}$ and $\mathrm{GPP}_{\mathrm{BM}}$, except for a minor effect of the variables used to model Rwood $(P=0.086)$ (Table 3$)$. As for Reco, the use of daytime flux data, instead of night time flux data, for the calculation of $\mathrm{GPP}_{\mathrm{EC}}\left(\mathrm{GPP}_{\mathrm{EC}}=\mathrm{Reco}_{\mathrm{EC}}+\mathrm{NEP}_{\mathrm{EC}}\right)$ improved the difference between $\mathrm{GPP}_{\mathrm{EC}}$ and $\mathrm{GPP}_{\mathrm{BM}}$ (from $5 \pm 5 \%$ to $2 \pm 2 \%)$. However, this change was non-significant $(P=0.81)$ mainly because daytime-data derived $\mathrm{GPP}_{\mathrm{EC}}$ did not differ than night time-data derived $\mathrm{GPP}_{\mathrm{EC}}\left(2 \pm 2 \%\right.$, daytime $\mathrm{GPP}_{\mathrm{EC}}>$ night time $\left.\mathrm{GPP}_{\mathrm{EC}}, P=0.91\right)$.

\section{Discussion}

Here we will discuss four major points: the insight that our analysis provides on $\mathrm{EC}$ and on $\mathrm{BM}$, the low convergence between $\mathrm{NEP}_{\mathrm{EC}}$ and $\mathrm{NEP}_{\mathrm{BM}}$, the EC-BM convergence for Reco and GPP and the different degree of the methodological convergence observed for NEP, Reco and GPP.

As no recognized reference method exists for $\mathrm{CO}_{2}$ exchange in ecosystems, in principle, it is not possible to evaluate the correctness of EC in measuring NEP, and in assessing Reco and GPP. However, our study provided several indirect indications about the general reliability of EC-based estimates of $\mathrm{C}$ fluxes. For example, the lack of correlation of the difference between EC- and BM-based estimates of $\mathrm{C}$ fluxes versus site topographical complexity and LAI suggests that the standard post-processing 
procedures used to account for advective and low-frequency flows of $\mathrm{CO}_{2}$ are effective. In fact, without the appropriate amendment, increasing site topographical complexity and LAI should increase the chances of advective and low-frequency flows of $\mathrm{CO}_{2}$, causing biases in EC estimates ${ }^{5,6}$. These issues, which can be relevant for particular sites 8,18 , are therefore less important at multiple-site level. Another indication about the reliability of EC-based C fluxes is that, estimates of $\operatorname{Reco}_{\mathrm{EC}}$ (and $\mathrm{GPP}_{\mathrm{EC}}$ ) based on daytime flux data do not differ significantly from estimates of $\operatorname{Reco}_{\mathrm{EC}}$ (and $\mathrm{GPP}_{\mathrm{EC}}$ ) based on night time flux data (as was also demonstrated elsewhere ${ }^{9}$ ), and their use here does not improve the convergence between EC and BM. This specifically supports that problems related to low-turbulence conditions during night are in general sufficiently amended by the flux data treatment ${ }^{5}$. Finally, the lack of major divergence between night time estimated Reco $_{\mathrm{EC}}$ and Reco $_{\mathrm{BM}}$ further reduce the probability that estimates of $\mathrm{NEP}_{\mathrm{EC}}$ are affected by major night time overestimation, at least for temperate and tropical forests.

Contrary to EC, no standard procedures exist for BM and the BM studies included in our synthesis presented different approaches in determining the production and respiration components of the ecosystem C cycle. The methodological variation in BM was important and allowed us to detect which approach best converged with EC. Measurements of respiration were particularly affected by the methodological approach. For Rsoil (which represents the dominant component of Reco), it is known that the NSNF chamber system significantly underestimates Rsoil, whereas the NSF system presents smaller inaccuracies ${ }^{19}$. This was indirectly reflected by our results. As $\mathrm{Reco}_{\mathrm{BM}}$ was overall larger than $\mathrm{Reco}_{\mathrm{EC}}$, the agreement of these estimates when the NSNF system was used indicates a potential case of error compensation, with the underestimation of belowground respiration compensating an overestimation of aboveground respiration (see below). On the other hand, the latter term was not compensated when the NSF was used, with $\mathrm{Reco}_{\mathrm{BM}}$ having larger values than $\mathrm{Reco}_{\mathrm{EC}}$ at sites making use of NSF. Leaf respiration is also an important component of Reco (about 30\%). Our data show that, the consideration or not in BM of light inhibition of daytime Rleaf (it was considered in only $28 \%$ of our sites) has a major influence on the convergence between $\mathrm{Reco}_{\mathrm{EC}}$ and $\mathrm{Reco}_{\mathrm{BM}}$. This is striking as light inhibition of daytime Rleaf is also neglected in standard (night time derived) estimates of Reco and might not be correctly accounted for even in the daytime derived $\operatorname{Reco}^{20}$. A possible explanation is that error compensation might reduce the impact of neglecting light inhibition of Rleaf more in EC- than BM-based estimates (for example, the overestimation caused by not accounting for the light inhibition of Rleaf might be compensated by missing fluxes), and should be examined further. On the other hand, our analysis did not show major issues related to scaling in BM-based estimates of respiration. For instance, Rwood, the Rwood:Reco ratio and the convergence between $\mathrm{Reco}_{\mathrm{BM}}$ and $\mathrm{Reco} \mathrm{EC}_{\mathrm{EC}}$ were not related to the scaling variable used for the wood respiration rate (stand wood volume or wood surface area, $P=0.3-0.8$; Table 3; Supplementary Table 6). On the other hand, for the leaf respiration rate that is typically scaled up using estimates of LAI, Rleaf, the Rleaf:Reco ratio and the convergence between $\mathrm{Reco}_{\mathrm{BM}}$ and $\mathrm{Reco}_{\mathrm{EC}}$ did not vary between needleleaved and broadleaved species $(P=0.2-0.3$; Table 3 ; Supplementary Table 6). This is the case even though the leaf area estimates of needle-leaved species are more prone to biases than for broadleaved species ${ }^{21}$.

Methodological variants in measuring NPP did not show any significant impact on the convergence between EC and BM. For wood, flaws in allometric relationships can cause either overestimation or underestimation of $\mathrm{NPP}^{22}$ and thus errors are compensated when multiple sites are considered. For leaves, the use of the litter trap method did not seem to provide different production estimates for deciduous or evergreen stands, as they show practically the same leaf-to-aboveground production ratio $(0.45 \pm 0.03$ and $0.45 \pm 0.02$, respectively; $P=0.99)$. On the other hand, the use of litter traps or allometric relationships resulted in different leaf-to-aboveground production ratio in evergreen stands $(0.32 \pm 0.06$ and $0.45 \pm 0.02$, respectively; $P=0.022)$. This indicates that these two methodologies may provide different estimates of leaf NPP for evergreen species but also that this systematic difference is too small to affect the EC-BM convergence for NEP and GPP (Table 3). For fine roots, our results did not show the typical bias pattern associated with the different methods to measure NPP (for example, underestimations for ingrowth cores and overestimation for minirhizotron ${ }^{23}$ ), which may be due to the overall large uncertainty in fine root NPP estimates.

Our study generally finds good support for the reliability and consistency of EC and BM approaches to estimate forest $\mathrm{C}$ fluxes at the ecosystem level. However, the low convergence recorded between $\mathrm{NEP}_{\mathrm{EC}}$ and $\mathrm{NEP}_{\mathrm{BM}}$, with $\mathrm{NEP}_{\mathrm{EC}}$ significantly larger than $\mathrm{NEP}_{\mathrm{BM}}$ for extratropical forests, is an important exception. For temperate forests, the mean difference was $100 \mathrm{gCm}^{-2} \mathrm{y}^{-1}$, which is broadly comparable to the inter-annual variability for this biome $13,17,24$, characterized by NEP of about $300-400 \mathrm{gC} \mathrm{m}^{-2} \mathrm{y}^{-1}$ (ref. 25). For the boreal zone, the mean difference was about $170 \mathrm{gC} \mathrm{m}^{-2} \mathrm{y}^{-1}$, which is sufficiently large to confound the ecosystem sink-source status as NEP of boreal forests is typically between 40 and $180 \mathrm{gC} \mathrm{m}^{-2} \mathrm{y}^{-1}$ (ref. 25). For instance, the mean $\mathrm{NEP}_{\mathrm{BM}}$ of the boreal sites in our data set was $-60 \pm 60 \mathrm{gC} \mathrm{m}^{-2} \mathrm{y}^{-1}$ (C source) whereas the mean $\mathrm{NEP}_{\mathrm{EC}}$ was $110 \pm 40 \mathrm{gC} \mathrm{m}^{-2} \mathrm{y}^{-1}$ (C sink). The reason for this pattern is not clear, as we did not observe significant relationships between the low convergence between $\mathrm{NEP}_{\mathrm{EC}}$ and $\mathrm{NEP}_{\mathrm{BM}}$ and climatic or environmental variables (such as mean annual temperature, mean annual precipitation and site fertility, which are all lower in the boreal zone). Probably, the relatively small $\mathrm{C}$ fluxes in boreal forests make them more susceptible to methodological biases.

As we did not find any indications for major overestimations of $\mathrm{NEP}_{\mathrm{EC}}$, it is relevant to explore if the dominant $\mathrm{BM}$ approach used to measure NEP is affected by any systematic underestimation that could explain the difference between $\mathrm{NEP}_{\mathrm{EC}}$ and $\mathrm{NEP}_{\mathrm{BM}}$. As the usual approach to estimate $\mathrm{NEP}_{\mathrm{BM}}$ is by subtracting heterotrophic respiration (Rh-soil and $\mathrm{Rh}$-cwd) from $\mathrm{NPP}$, underestimation of $\mathrm{NEP}_{\mathrm{BM}}$ could be caused by overestimation of Rh-soil and Rh-cwd or underestimation of NPP. $\mathrm{Rh}$-cwd is a relatively small flux in most sites and we have not recorded lower agreement between $\mathrm{NEP}_{\mathrm{BM}}$ and $\mathrm{NEP}_{\mathrm{EC}}$ for sites missing this component of the $\mathrm{C}$ cycle. Ecosystem $\mathrm{Rh}$-soil is particularly difficult to measure and, in our data set, four major measurements approaches were used: root exclusion to estimate Rh-soil ( $60 \%$ of sites), measuring Rroot and then subtracting it from Rsoil (20\% of sites), calculating Rh-soil from separate incubation of all components of the soil except roots $(10 \%$ of sites) and applying a fixed Rh-soil:Rsoil ratio (10\% of sites) (see Methods for details). All these approaches have methodological uncertainties ${ }^{26}$. However, the fact that the difference between $\mathrm{NEP}_{\mathrm{BM}}$ and $\mathrm{NEP}_{\mathrm{EC}}$ was not affected by the four approaches to measure Rh-soil (Table 3) and that all four approaches presented an underestimation of $\mathrm{NEP}_{\mathrm{BM}}$ very similar to the global difference between $\mathrm{NEP}_{\mathrm{BM}}$ and $\mathrm{NEP}_{\mathrm{EC}}$ (Supplementary Fig. 2), point towards the conclusion that the low convergence between $\mathrm{NEP}_{\mathrm{BM}}$ and $\mathrm{NEP}_{\mathrm{EC}}$ is more likely to be related to underestimation of NPP than overestimation of Rh-soil. Underestimation of NPP is indeed considered as a key potential source of bias in the BM approach to estimate NEP (see Introduction). An analysis of the 
primary factors possibly causing NPP underestimation based on the literature indicated that, on average, our NPP values might be underestimated by roughly $20 \%$ because incomplete assessment of mycorrhiza NPP and NPP related to branch turnover, which were taken into account in only very few of the sites (see Methods). Furthermore, additional underestimation could have been caused by minor NPP components typically neglected (for example, root exudation, net accumulation of non-structural carbohydrates, herbivory consumption, production of volatile organic compounds ${ }^{22}$, which in general contribute between 1 and $4 \%$ of $\mathrm{NPP}^{16,27-29}$. The low convergence between $\mathrm{NEP}_{\mathrm{EC}}$ and $\mathrm{NEP}_{\mathrm{BM}}$, when $\mathrm{NEP}_{\mathrm{BM}}$ was obtained from NPP and $\mathrm{Rh}$, and the difficulty in quantifying NPP, suggests that stock change approaches may be a valid BM alternative to quantify NEP. For example, even if this analysis was less robust because of the small sample size, we discovered that when $\mathrm{NEP}_{\mathrm{BM}}$ was based on repeated stock inventories, the difference between EC- and BM-based estimates of NEP was not statistically significant.

Except for Reco in the boreal zone (as mentioned above), estimates of Reco and GPP did not show significant differences between methods. This high methodological convergence increases the confidence in the knowledge gained using only $\mathrm{EC}^{10,11}$ or $\mathrm{BM}^{12,13}$ and favours the integration of $\mathrm{EC}-$ and BM-based estimates in synthesis studies, model-data fusion and model development. The higher EC-BM convergence for Reco and GPP than NEP might appear counter-intuitive at first, as Reco and GPP are derived from NEP (for EC) or rely on the measurements of the same component processes of NEP (for BM). However, the different degree of EC-BM convergence among the carbon fluxes is coherent with our results and likely related to the small magnitude of NEP and to the partial offset of errors of opposite direction for Reco and GPP. On the one hand, the magnitude of NEP fluxes is only about $15-20 \%$ of the magnitude of Reco and GPP. Therefore, NEP estimates can be more susceptible than Reco and GPP to methodological inaccuracies. On the other hand, it is important to realize that high convergence of Reco and GPP is not definitive proof of lack of systematic biases, but could be caused by error compensation. Three examples can be provided. For GPP ${ }_{\mathrm{BM}}$, the underestimation of NPP (discussed above) might be compensated for by overestimation of autotrophic respiratory fluxes, such as Rleaf (Fig. 3b,c). For $\operatorname{Reco}_{\mathrm{BM}}$, overestimation of Rleaf may be compensated for by an underestimation of Rsoil


overlooking the light inhibition of Rleaf, might be offset by missing $\mathrm{CO}_{2}$ fluxes. Overall, the compensating aspects of Reco and GPP are not important for landscape- and large-scale assessment of ecosystem $\mathrm{CO}_{2}$ fluxes but should nonetheless be investigated in depth at site-level so that experimentalists can better evaluate the measurement strategy and modelers have the appropriate information on key ecosystem $\mathrm{C}$ cycle processes.

\section{Table 4 | Risk of lack of convergence between estimates of forest carbon fluxes obtained from eddy-covariance and biometric methods according to site and methodological characteristics.}

Flux

Variables

Overall

NEP

Reco

GPP

Climate zone

$\begin{array}{lr}\text { NEP } & \text { Boreal } \\ \text { Reco } & \text { High } \\ \text { HPP } & \text { High }\end{array}$

GPP

Canopy features

NEP

Reco

GPP

Leaf type*
Low
Low
Low

Topography and soil characteristics

NEP

Reco

GPP

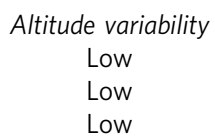

Compartment measured with biometric methods

$\begin{array}{lc}\text { NEP } & \text { Leaves } \\ \text { Reco } & \text { Low } \\ \text { GPP } & \text { Highll }\end{array}$

\section{High \\ Moderate \\ Low}

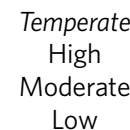

Tropical

Low

Low

Low
Leaf area index
Low
Low
Low

Fertility

Low

Low

Low

The risk of lack of convergence between eddy-covariance (EC) and biometric methods (BM) estimates of net ecosystem production (NEP), ecosystem respiration (Reco) and gross primary production (GPP) for forests is reported according to climatic zone, canopy features, site (topography and soil) characteristics, and the main ecosystem compartments measured with BM, and expressed in three levels: low (non-significant difference between BM and EC estimates and/or lack of systematic biases), moderate (difference between the BM and EC estimates at $0.05<P<0.10$ and/or potential of systematic biases) and high (significant difference at $P<0.05$ between the $\mathrm{BM}$ and $\mathrm{EC}$ estimates and/or systematic biases).

systematic biases) and high (significant

$\dagger$ Evergreen, deciduous or mixed.

¡Not considering branch turnover in estimates of net primary production (but with an adequate assessment of the other components of the wood production, see Methods)

§Not considering mycorrhizal production (but with an adequate assessment of root production, see Methods).

||Not considering light inhibition of leaf dark respiration.

- Use of lower quality chamber system to measure soil respiration. 
In conclusion, our study has shown four key findings. First, forest NEP estimates obtained with BM and EC differ significantly, particularly for the boreal zone, where the source/sink status is sensitive to the measurement technique. Second, BM and EC-based estimates of Reco and GPP are globally comparable for forest ecosystems but error compensation is likely to play a role in the convergence. Third, there are indirect but multiple indications that the potential biases associated with $\mathrm{EC}$ are, in aggregate, sufficiently amended by post-processing of the data. Fourth, BM approaches underestimating NPP and neglecting light inhibition of leaf dark respiration show less convergence with EC estimates. Our results also provide manifold information with important practical implications, as they identify in which situations forest $C$ fluxes can be measured with both EC and BM methodologies (with the choice of the method depending on factors such as scientific objectives, logistics, local researcher capacity and availability of labour) and it is safe to integrate EC- and BM-based C flux estimates in synthesis studies or model-data fusion (Table 4). On the other hand, we report the mean values of difference against which the discrepancy between EC and BM can be tested in cases of low convergence (for example, for boreal forests) and which methodological aspects need to be taken most urgently into account to improve the convergence between EC and BM. Finally, we make also available the uniform forest $\mathrm{C}$ cycle data set that we compiled using quality-checked EC and BM data. All these evidences, elucidations and tools will substantially improve our ability to assess and simulate the $\mathrm{CO}_{2}$ exchange of terrestrial ecosystems.

\section{Methods}

Overview study data set. We constructed a data set of NEP, Reco and GPP obtained from BM and EC methodologies. The data set contains annual flux estimates, uncertainties, key information about the measurement techniques and ancillary data on environmental and stand variables. Data were retrieved from ISI-Web literature and existing databases such as the global database of forest $\mathrm{C}$ cycle $^{25}$, FLUXNET ${ }^{30}$ and the European Flux Database Cluster ${ }^{31}$.

EC data are consistent as calculated through standard procedures, quality-check and data processing 5 . However, the NEP partitioning methods used to produce Reco and GPP can vary substantially and we classified them into three categories: methods based on night time data following Reichstein et al. ${ }^{10}$ or very similar algorithms ${ }^{32-34}$, methods based on daytime data following Lasslop et al. ${ }^{9}$ and calculation of Reco from sundown respiration following van Gorsel et al. ${ }^{35}$. As the latter method was only applied at two sites, the analyses on the partitioning method were actually focused on the night time and daytime methods only. Contrary to $\mathrm{EC}$, no standard procedures exist for $\mathrm{BM}$ and data in the literature are highly heterogeneous, reflecting their diverse scope (for example, assessing the impact of a manipulative experiment, stand level estimates, regional assessments), local researcher capacity and practical reasons (for example, logistics, availability of labour). To obtain a uniform and quality-checked BM data set, we performed three operations. First, we retrieved details on BM for each site and classified them in multiple categories of methodological approach and up-scaling methods. Second, we considered in the analysis only sites fulfilling a pre-defined set of data quality criteria. Third, we related the data uncertainty to the technique adopted. Full details about the BM data set and its construction are reported below in four sections: annual estimates of production and respiration in BM data set, variables of BM data set for estimation of flux uncertainty, methodological variants of BM approach, and NEP biometric data from stock inventories.

The key environmental and stand variables used in the analysis are two indices of topographical complexity (that is, elevation variability and topographical slope) and LAI, which are thought to be related to bias in the EC-based estimates of C fluxes (see Introduction). The indices of topographical complexity were measured within a $2,430 \times 2,430 \mathrm{~m}$ quadrat, centered at the EC tower, obtained from NASA ASTER DEM data ${ }^{36}$. The elevation variability was the standard deviation of the elevation of 729 pixels composing the quadrat. The topographical slope was derived from the elevation and distance of the highest and lowest pixels within the quadrat. The LAI was derived from the literature. The other variables tested for possible systematic influences on EC and BM include leaf characteristics, climatic features and site fertility. Leaf characteristics refer to leaf habit (evergreen, deciduous or mixed) and leaf type (needleleaved, broadleaved or mixed), which might affect the measurement of $\mathrm{LAI}^{21}$ and, consequently, the upscaling of leaf measurements to the stand level. Climatic features comprise climate zone (boreal, temperate or tropical), mean annual temperature and mean annual precipitation, which might affect both the instrument performance and the post-processing of the data (which involve different type of modelling and extrapolations) $)^{5,37}$. Site fertility was considered because it was recently found as the key driver of the $\mathrm{CO}_{2}$ exchange in forests ${ }^{38}$. It was classified in three categories (infertile, moderately fertile or fertile) based on soil type, physicochemical soil properties, and human amendments/degradation ${ }^{29,38,39}$. All the environmental and stand variables were derived from the literature or other databases and are reported in Supplementary Table 4 and Supplementary Data 1.

Annual estimates of production and respiration in BM data set. The main component processes of the ecosystem $\mathrm{C}$ cycle considered are: NPP, aboveground $\mathrm{Ra}$, Rsoil and its components (root autotrophic respiration, Rroot and Rh-soil) and Rh-cwd:

$$
\text { aboveground } \mathrm{Ra}=\text { Rleaf }+ \text { Rwood }
$$

Rsoil $=$ Rroot + Rh-soil

These variables are combined to obtain NEP, Reco and GPP

$$
\begin{gathered}
\mathrm{NEP}=\mathrm{NPP}-\mathrm{Rh}=\mathrm{NPP}-\mathrm{Rh} \text {-soil }-\mathrm{Rh}-\mathrm{cwd} \\
\mathrm{Reco}=\mathrm{Ra}+\mathrm{Rh}=\text { aboveground } \mathrm{Ra}+\text { Rsoil }+\mathrm{Rh}-\mathrm{cwd} \\
\mathrm{GPP}=\mathrm{NPP}+\mathrm{Ra}=\mathrm{NPP}+\text { aboveground } \mathrm{Ra}+\text { Rroot }
\end{gathered}
$$

A full list of the variables (for example, NPP, Ra) for each ecosystem component (for example, foliage, wood, fine roots, soil) is reported in Supplementary Table 7 The methods used to measure these variables are briefly reported below, whereas extended methodological information for each site (for example, set-ups and measuring protocols, methods used to integrate point measurements to annual scale, methods to scale up tree level data to the stand level) is reported in Supplementary Methods. For sites with multiple-years data of NEP, Reco and GPP but with a combination of direct and indirect measurements, only years with direct measurements were considered.

Net primary production. Sites were selected when at least the three major components of the ecosystem production were measured: wood NPP, foliage NPP and fine root NPP. Wood NPP (stem, branches and coarse roots) was obtained as the increment in wood standing biomass from consecutive tree size (typically diameter) surveys and allometric relationships between tree size and wood standing biomass. Detailed information about the allometric relationships used at each site is reported in Supplementary Table 8. The quality of the relationships was classified into three categories according to their degree of species-specificity (species-specific versus generic), their geographical origin (site-specific versus regional) and their degree of flexibility (full dependency on tree size versus partial use of fixed productivity ratios). The categories are: high quality, for species- and site-specific relationships without fixed productivity ratios; moderately quality, for speciesspecific relationships without fixed productivity ratios but not site-specific, and low quality, for generic and/or not site-specific relationships employing also fixed productivity ratios. Foliage NPP was typically obtained from leaf litter collected with litter traps (for both deciduous and evergreen species) or from tree size surveys and allometric relationships between tree size and current-year leaf biomass (for evergreen species). Fine root NPP was measured with different methods, which can be classified into three main categories: sequential coring ${ }^{40}$ (for $26 \%$ of our sites), minirhizotron-based technique ${ }^{41}$ (23\% of sites) and ingrowth cores $^{42}$ (19\% of sites). In addition, we aggregated the other techniques (for example, process-based modelling ${ }^{43}$, empirical modelling ${ }^{44}$, mass balance approach ${ }^{45}$ ) in a fourth category named other methods. For a comparison across methods see Milchunas ${ }^{23}$. Only sites with site-specific estimates of wood, foliage and fine root NPP were included. Therefore, sites with fine root NPP derived from aboveground NPP, generic algorithms or global models were not considered. The majority of the sites $(70 \%)$ meeting the requirement on wood, foliage and fine roo NPP also presented understory NPP (generally measured with a combination of allometric relationships between plant dimension and biomass and/or harvest techniques ${ }^{17}$ ). NPP due to branch turnover (from branch fall surveys), reproductive organs (from litter traps) and herbivory (from leaf area or biomass consumption) was considered in $30-40 \%$ of the sites. NPP due to production of volatile organic compounds and mycorrhizae production was considered in only $10 \%$ of the sites.

Aboveground respiration. To be included in our quality-checked BM data set, sites needed to comprise at least site-specific estimates of Rleaf and Rwood, fully independent to EC data. Rleaf was typically measured with chambers and infrared gas analyser, in situ, on canopy leaves ${ }^{37,46}$, or in vitro, on leaves of freshly cut branches ${ }^{42,47}$. Rwood was always measured with chambers and infrared gas analyser. Measurements were typically performed during various occasions in the growing and dormant season and integrated at annual level by using empirical models that related respiration to temperature, water status or other environmental variables ${ }^{37}$. Data were scaled up at stand level using LAI or leaf biomass, for Rleaf, and sapwood volume or area, for Rwood. About $60 \%$ of the sites presented also measurements of understory respiration $(\mathrm{Ru}$; absence of $\mathrm{Ru}$ data was however not considered as a criterion for excluding the site). Measurement methods of Ru were similar to the ones for Rleaf and Rwood, and, often, Ru data were not presented separately but included into Rleaf and Rwood.

Belowground respiration. Rsoil was needed for a site to be included in our $\mathrm{ReCO}_{\mathrm{BM}}$ data set, whereas partitioning into Rroot and Rh-soil was needed for 
inclusion in the data set of $\mathrm{GPP}_{\mathrm{BM}}$ and $\mathrm{NEP}_{\mathrm{BM}}$, respectively (Supplementary Table 7). Rsoil was measured by using various soil chamber systems which fall into three major categories: closed static chambers or NSNF, closed dynamic chambers or NSF, and open dynamic chambers or steady-state through-flow chamber ${ }^{19}$. However, because the latter system was only used in two of our sites, we did not consider this system in our statistical analysis. On the other hand, for the NSF technique, we further classified the sites into two groups, according to whether the system prescribed scrubbing of $\mathrm{CO}_{2}$ before the flux measurements (for example, Li-Cor LI-6400-09 system; LI-COR Biosciences, Lincoln, USA) or not ${ }^{19}$. Measurements not performed continuously were integrated at annual scale using empirical models relating soil respiration to temperature and/or soil water status. Various methods were applied to partition Rsoil into Rroot and Rh-soil. We grouped them into four categories: root exclusion methods (used in 57\% of the sites), that directly measure Rh-soil in situ and indirectly derive Rroot from equation (2); estimation of Rroot (20\% of sites), both in situ (using root chambers), in vitro (using excised roots) or using models (process-based or empirical models) and indirectly deriving $\mathrm{Rh}$-soil from equation 2; component integration (10\% of sites), that prescribes the estimation of Rh-soil from the respiration of all components of the soil (for example, litter, mineral soil layers and so on) separately, often in vitro in the laboratory, and, as for the exclusion methods, indirectly estimates Rroot (equation (2)), and other methods, which mainly assume a fixed ratio between Rroot and Rh-soil ${ }^{26}$. See Hanson et al. ${ }^{26}$ for more details on all methods to partition Rsoil into Rroot and Rh-soil.

Other respiratory components. Decomposition of coarse woody debris (Rh-cwd) can be a significant part of the total ecosystem respiration. Rh-cwd was therefore considered when reported (for $65 \%$ of the sites) but sites missing it were not excluded. Rh-cwd was typically derived from surveys of standing dead wood and estimates of decays rates, or, in a minority of cases, from chamber measurements of $\mathrm{CO}_{2}$ exchange or wood decomposition from successive surveys.

Variables of BM data set for estimation of flux uncertainty. Data uncertainty of NEP, Reco and GPP was calculated following the method described below. The data required for the estimation of the flux uncertainty are: the site latitude, the number of replicated years of measurement, and a general label of data quality. The latter has two levels: high quality data, for sites with only site-specific measurements, or fair quality data, for sites with measurements comprising also not site-specific relationships and/or models.

Methodological variants of BM approach. BM data were often obtained at different sites with different BM techniques or data processing. Therefore, we reported in the BM data set the employed approach for each site and measured variable. This was done to analyse the impact of the BM methodology on the convergence between EC and BM fluxes. In particular, we considered 17 methodological variants of the BM technique (Table 3). For this analysis, we paid more attention to variables that had a large numerical impact on the stand $\mathrm{C}$ cycle (for example, Rsoil, fine root NPP, Rleaf, Rh-soil), whereas we paid less attention to variables that had a small numerical impact (for example, Rwood, Rh-cwd).

NEP biometric data from stock inventories. $\mathrm{NEP}_{\mathrm{BM}}$ is not only obtainable from measurements of production and respiration (equation (3)) but also derivable from the difference in ecosystem $\mathrm{C}$ stocks between two points in time ${ }^{12}$. $\mathrm{NEP}_{\mathrm{BM}}$

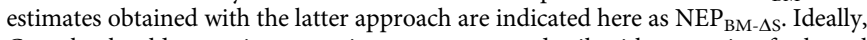
$\mathrm{C}$ stocks should comprise vegetation, necromass and soil, with correction for lateral $\mathrm{C}$ losses (for example, harvests, leaching of dissolved organic carbon) ${ }^{48}$. In practice, complete $\mathrm{C}$ stock inventories are seldom done. Therefore, we included in the $\mathrm{NEP}_{\mathrm{BM}-\Delta \mathrm{S}}$ data set all sites in the literature $(n=7)$ with the repeated assessment of at least the two major ecosystem $\mathrm{C}$ stocks that is, wood and soil.

Data uncertainty. As flux uncertainty was available only for a minority of sites (and its calculation method was highly inconsistent among studies), the uncertainties in fluxes were approximated uniformly following Luyssaert et al. ${ }^{25}$ These authors proposed that the flux uncertainty for a site $(s)$ can be approximated by considering three elements. First, the typical range of the flux value for the site biome $(p)$ set as the maximal potential uncertainty range. Second, a reduction factor $(\mathrm{RF})$, depending on the measuring methodology, that reduces the maximal potential uncertainty range (for example, a precise method would reduce the uncertainty interval more than an imprecise method). Third, the number of measurement years $(l)$, with more replicate-years reducing the uncertainty interval. Thus:

$$
s=\frac{p \times \mathrm{RF}}{\sqrt{l}}
$$

For example, to determine the $\mathrm{NEP}_{\mathrm{EC}}$ uncertainty of a temperate forest with two years of measurements, the Luyssaert $e t$ al.'s approach considers that NEP of temperate forests typically ranges between -100 and $600 \mathrm{gC} \mathrm{m}^{-2} \mathrm{y}^{-1}$ (thus $\left.s=p= \pm 350 \mathrm{gCm}^{-2} \mathrm{y}^{-1}\right)$, that EC is precise and reduces the uncertainty to $30 \%$ of the baseline value $\left(\mathrm{RF}=0.3\right.$, thus $\left.s= \pm 105 \mathrm{gC} \mathrm{m}^{-2} \mathrm{y}^{-1}\right)$ and that the presence of two measurement years further reduces the uncertainty to $s= \pm 74 \mathrm{gC} \mathrm{m}^{-2}$ $\mathrm{y}^{-1}$. In general, according to this method, $p$ of NEP is assumed to be $350 \mathrm{gC} \mathrm{m}^{-2}$ and GPP depends on latitude and varies from 500 to $1000 \mathrm{gCm}^{-2} \mathrm{y}^{-1}$ (ref. 25), and that $R F$ of $\mathrm{BM}$ is 0.3 , as for $\mathrm{EC}$, for sites with high quality data and 0.6 for sites with fair quality data (see above).

The adopted approach produces uncertainty intervals comparable to the directly estimated uncertainty for $\mathrm{EC}^{25}$. Here, we observed that good agreement was achieved also for the BM fluxes of extratropical forests but that relevant mismatches were detected for Reco and GPP of tropical sites where the Luyssaert et al.'s approach underestimated the measured uncertainty by $60-70 \%$

(Supplementary Table 9). We considered this important discrepancy not crucial for our analysis because we had only four tropical sites and repetition of the analysis with corrected uncertainty values of tropical sites (to match the directly estimated uncertainty) did not change the main results (data not shown).

Data analysis. The data were analysed in four steps, which are described below. For each case, note that the comparison of the EC and BM fluxes was performed for sites with data referring to the same vegetation cover (or footprint) and to the same period or with minor temporal mismatches (for example, BM fluxes available for a three-year period and EC fluxes for a 2-year period) generally considered suitable for the EC and $\mathrm{BM}$ comparison by the original investigators (for $74 \%$ of the sites the BM and EC data were from published EC-BM comparison at the site-level).

Agreement between EC and BM. We obtained a first indication of the agreement between EC- and BM-data by calculating the regression of BM versus EC estimates along the entire range of flux measurements. Major-axis regressions were used because both variables had error terms of similar magnitude ${ }^{49}$. Agreement was inferred from the slope of the regression line and the correlation indicated by $R^{2}$. In addition, for each flux and climatic zone, the agreement between the EC and BM estimates was more stringently tested by a paired $t$-test (in case the differences between pairs were normally distributed according to Shapiro-Wilks' test) or Wilcoxon signed-rank test (in case the differences between pairs were not normally distributed). The same approach was used to compare $\mathrm{NEP}_{\mathrm{EC}}$ and $\mathrm{NEP}_{\mathrm{BM}-\Delta \mathrm{S}}$ (see above).

Impact of environmental and stand variables on the $\mathrm{EC}$ and $\mathrm{BM}$ convergence. We tested whether the difference between the EC- and BM-based estimates was systematically related to elevation variability and topographical slope (indices of topographical complexity), LAI, leaf habit and leaf type (canopy characteristics), climate zone, mean annual temperature and mean annual precipitation (climate variables) and site fertility (see above). The tests comprised univariate analyses performed regressing (with an ordinary least squares regression) the difference between the EC- and BM-based estimates and each variable, separately. To fully exploit the information available for each site, the impact of flux data uncertainty was added to the analysis by using the inverse of the flux uncertainty as weighing factor among sites (thus giving lower weight to sites with higher uncertainty on the estimates). Each analysis met the normality of residuals (tested with Shapiro-Wilks test) and the assumption of homoskedasticity (tested with Breusch-Pagan test), except in a few cases for which the White method (for heteroskedasticity correction) was used instead ${ }^{50}$

Impact of different methodological variants on the convergence between EC and BM. The impact of different methodological approaches on the convergence between EC and BM-based estimates was tested as above with ordinary least squares regressions weighted by the inverse of the flux uncertainty. These univariate analyses served well for the purpose of the study, as preliminary analyses showed typically no relevant two-term interactions. The few significant $(P<0.05)$ two-terms interactions ( 1 out 55 cases for GPP, 5 out of 66 for Reco and 1 out of 6 for NEP) did not have logical meaning but were related to the small sample size, that is, singularities. The only exception was represented by a significant interaction between soil respiration chamber type and accounting for light inhibition of leaf respiration for Reco, which was considered in the data analysis (see Results). For $\mathrm{BM}$, the methodological variants were 17 (Table 3). For EC, the only methodological variant was the NEP partitioning method which was of two types (see above).

Analysis of NPP data. NPP is a key component for the determination of $\mathrm{NEP}_{\mathrm{BM}}$ and $\mathrm{GPP}_{\mathrm{BM}}$. Five methodological flaws can typically have a significant $(>10 \%)$ and unidirectional (underestimation) impact on NPP estimates in forests ${ }^{22}$ : not accounting tree mortality, assuming life span of fine roots to be 1 year, coarse measurements of leaf NPP in tropical forests, not measuring mycorrhizal NPP and rhizodeposition, and not correcting for NPP related to branch turnover. The first three cases are less relevant in our data set as: site tree mortality was normally assessed, fine root production was estimated for each site and tropical sites are few in our data set and their leaf NPP was quantified accurately. On the other hand, we detected than only three and six sites (out of 31) took into account mycorrhizal NPP and NPP related to branch turnover, respectively. The impact of these missing terms was estimated by gap-filling the original NPP values using the average values of branch turnover related NPP from our data set (which was equivalent to $22 \%$ of aboveground wood NPP or $8 \%$ of total NPP, $n=6$; Supplementary Table 2) and of mycorrhizal NPP from the literature (which was equivalent to $14 \%$ of total NPP, $n=6$, and in agreement with culture studies ${ }^{51}$; Supplementary Table 10). The gapfilled NPP estimates were on average $20 \%$ larger than the original NPP estimates

Overall, the analyses were performed for all fluxes, that is, NEP ( $\mathrm{NEP}_{\mathrm{BM}}$ versus $\mathrm{NEP}_{\mathrm{EC}}$ ), Reco (Reco ${ }_{\mathrm{BM}}$ versus Reco $\mathrm{EC}_{\mathrm{EC}}$ ) and GPP ( $\mathrm{GPP}_{\mathrm{BM}}$ versus $\left.\mathrm{GPP}_{\mathrm{EC}}\right)$. For Reco 
and GPP, to ensure that the impact of each given site was independent on the flux magnitude, the analyses were performed using the relative difference between the EC- and BM-based flux estimates (for example, for GPP: $\left(\mathrm{GPP}_{\mathrm{BM}}-\mathrm{GPP}_{\mathrm{EC}}\right)$ / $\left(\left(\mathrm{GPP}_{\mathrm{EC}}+\mathrm{GPP}_{\mathrm{BM}}\right) / 2\right)$. For NEP, the latter approach was impeded by the presence of both positive and negative values. We intentionally retained outliers in our analyses because they could represent cases with high discrepancy between the methodologies and thus of relevance for our scope. All analyses were performed within the $\mathrm{R}$ platform ${ }^{52}$.

Data availability. The data that support the findings of this study are included in Supplementary Data 1. Data are from the literature and public databases. Details about the data and the data sources are reported in Supplementary Tables 1-5.

\section{References}

1. Baldocchi, D. D. Assessing the eddy covariance technique for evaluating carbon dioxide exchange rates of ecosystems: past, present and future. Global Change Biol. 9, 479-492 (2003).

2. Chapin, III F. S. et al. Reconciling carbon-cycle concepts, terminology, and methods. Ecosystems 9, 1041-1050 (2006).

3. Baldocchi, D. Measuring fluxes of trace gases and energy between ecosystems and the atmosphere-the state and future of the eddy covariance method. Global Change Biol. 20, 3600-3609 (2014).

4. Baldocchi, D. et al. FLUXNET: a new tool to study the temporal and spatial variability of ecosystem-scale carbon dioxide, water vapor, and energy flux densities. Bull. Am. Meteorol. Soc 82, 2415-2434 (2001).

5. Aubinet, M., Vesala, T. \& Papale, D. Eddy Covariance: A Practical Guide to Measurement and Data Analysis (Springer, 2012).

6. Aubinet, $\mathrm{M}$. Eddy covariance $\mathrm{CO}_{2}$ flux measurements in nocturnal conditions: an analysis of the problem. Ecol. Appl. 18, 1368-1378 (2008).

7. Finnigan, J. J. \& Belcher, S. E. Flow over a hill covered with a plant canopy. Q. J. Roy. Meteor. Soc 130, 1-29 (2004).

8. Thomas, C. K., Martin, J. G., Law, B. E. \& Davis, K. Toward biologically meaningful net carbon exchange estimates for tall, dense canopies: multi-level eddy covariance observations and canopy coupling regimes in a mature Douglas-fir forest in Oregon. Agr. Forest Meteorol. 173, 14-27 (2013).

9. Lasslop, G. et al. Separation of net ecosystem exchange into assimilation and respiration using a light response curve approach: critical issues and global evaluation. Global Change Biol. 16, 187-208 (2010).

10. Reichstein, M. et al. On the separation of net ecosystem exchange into assimilation and ecosystem respiration: review and improved algorithm. Global Change Biol. 11, 1424-1439 (2005).

11. Hamilton, J. G. et al. Forest carbon balance under elevated $\mathrm{CO}_{2}$. Oecologia 131, 250-260 (2002).

12. Curtis, P. S. et al. Biometric and eddy-covariance based estimates of annual carbon storage in five eastern North American deciduous forests. Agr. Forest Meteorol. 113, 3-19 (2002).

13. Gough, C. M., Vogel, C. S., Schmid, H. P., Su, H. B. \& Curtis, P. S. Multi-year convergence of biometric and meteorological estimates of forest carbon storage. Agr. Forest Meteorol. 148, 158-170 (2008).

14. Hanson, P. J., Edwards, N. T., Tschaplinski, T. J., Wullschleger, S. D. \& Joslin, J. D. in North American Temperate Deciduous Forest Responses to Changing Precipitation Regimes. (eds Hanson, Paul J. \& Wullschleger, Stan D.) 378-395 (Springer-Verlag, 2003).

15. Xu, B., Yang, Y., Li, P., Shen, H. \& Fang, J. Global patterns of ecosystem carbon flux in forests: a biometric data-based synthesis. Glob. Biogeochem. Cycles 28, 962-973 (2014).

16. Malhi, Y. et al. Comprehensive assessment of carbon productivity, allocation and storage in three Amazonian forests. Global Change Biol. 15, 1255-1274 (2009).

17. Peichl, M., Brodeur, J. J., Khomik, M. \& Arain, M. A. Biometric and eddycovariance based estimates of carbon fluxes in an age-sequence of temperate pine forests. Agr. Forest Meteorol. 150, 952-965 (2010).

18. Speckman, H. N. et al. Forest ecosystem respiration estimated from eddy covariance and chamber measurements under high turbulence and substantial tree mortality from bark beetles. Global Change Biol. 21, 708-721 (2015).

19. Pumpanen, J. et al. Comparison of different chamber techniques for measuring soil $\mathrm{CO}_{2}$ efflux. Agr. Forest Meteorol. 123, 159-176 (2004).

20. Wehr, R. et al. Seasonality of temperate forest photosynthesis and daytime respiration. Nature 534, 680-683 (2016).

21. Jonckheere, I. et al. Review of methods for in situ leaf area index determination - Part I. Theories, sensors and hemispherical photography. Agr. Forest Meteorol. 121, 19-35 (2004).

22. Clark, D. A. et al. Measuring net primary production in forests: concepts and field methods. Ecol. Appl. 11, 356-370 (2001).

23. Milchunas, D. G. Estimating root production: comparison of 11 methods in shortgrass steppe and review of biases. Ecosystems 12, 1381-1402 (2009).
24. Novick, K. A. et al. On the difference in the net ecosystem exchange of $\mathrm{CO}_{2}$ between deciduous and evergreen forests in the southeastern United States. Global Change Biol. 21, 827-842 (2015).

25. Luyssaert, S. et al. $\mathrm{CO}_{2}$ balance of boreal, temperate, and tropical forests derived from a global database. Global Change Biol. 13, 2509-2537 (2007).

26. Hanson, P. J., Edwards, N. T., Garten, C. T. \& Andrews, J. A. Separating root and soil microbial contributions to soil respiration: a review of methods and observations. Biogeochemistry 48, 115-146 (2000).

27. Campioli, M. et al. Can decision rules simulate carbon allocation for years with contrasting and extreme weather conditions? A case study for three temperate beech forests. Ecol. Model. 263, 42-55 (2013).

28. Jones, D. L., Hodge, A. \& Kuzyakov, Y. Plant and mycorrhizal regulation of rhizodeposition. New Phytol. 163, 459-480 (2004).

29. Vicca, S. et al. Fertile forests produce biomass more efficiently. Ecol. Lett. 15, 520-526 (2012).

30. Fluxdata.org., www.fluxdata.org (2015).

31. European Fluxes Database Cluster., www.europe-fluxdata.eu (2015).

32. Arain, A. A. \& Restrepo-Coupe, N. Net ecosystem production in a temperate pine plantation in southeastern Canada. Agr. Forest Meteorol. 128, 223-241 (2005).

33. Barr, A. G. et al. Inter-annual variability in the leaf area index of a boreal aspen-hazelnut forest in relation to net ecosystem production. Agr. Forest Meteorol. 126, 237-255 (2004).

34. Curtis, P. S. et al. Respiratory carbon losses and the carbon-use efficiency of a northern hardwood forest, 1999-2003. New Phytol. 167, 437-455 (2005).

35. Van Gorsel, E., Leuning, R., Cleugh, H. A., Keith, H. \& Suni, T. Nocturnal carbon efflux: reconciliation of eddy covariance and chamber measurements using an alternative to the $\mathrm{u}^{*}$-threshold filtering technique. Tellus B 59, 397-403 (2007).

36. ASTER: advanced spaceborne thermal emission and reflection radiometer., http://asterweb.jpl.nasa.gov/gdem.asp (2015).

37. Khomik, M. et al. Relative contributions of soil, foliar, and woody tissue respiration to total ecosystem respiration in four pine forests of different ages. J. Geophys. Res. 115, G03024 (2010).

38. Fernández-Martínez, M. et al. Nutrient availability as the key regulator of global forest carbon balance. Nat. Clim. Change 4, 471-476 (2014).

39. Campioli, M. et al. Biomass production effciency controlled by management in temperate and boreal ecosystems. Nat. Geosci. 8, 843-846 (2015).

40. Ohtsuka, T., Negishi, M., Sugita, K., Iimura, Y. \& Hirota, M. Carbon cycling and sequestration in a Japanese red pine (Pinus densiflora) forest on lava flow of Mt. Fuji. Ecol. Res. 28, 855-867 (2013).

41. Dore, S. et al. Carbon and water fluxes from ponderosa pine forests disturbed by wildfire and thinning. Ecol. Appl. 20, 663-683 (2010).

42. Doughty, C. E. et al. The production, allocation and cycling of carbon in a forest on fertile terra preta soil in eastern Amazonia compared with a forest on adjacent infertile soil. Plant Ecol. Divers. 7, 41-53 (2014).

43. Law, B. E., Waring, R. H., Anthoni, P. M. \& Aber, J. D. Measurements of gross and net ecosystem productivity and water vapour exchange of a Pinus ponderosa ecosystem, and an evaluation of two generalized models. Global Change Biol. 6, 155-168 (2000).

44. Aber, J. D., Melillo, J. M., Nadelhoffer, K. J., McClaugherty, C. A. \& Pastor, J. Fine root turnover in forest ecosystems in relation to quantity and form of nitrogen availability - a comparison of two methods. Oecologia 66, 317-321 (1985).

45. Raich, J. W. \& Nadelhoffer, K. J. Belowground carbon allocation in forest ecosystems - global trends. Ecology 70, 1346-1354 (1989).

46. Maseyk, K., Grunzweig, J. M., Rotenberg, E. \& Yakir, D. Respiration acclimation contributes to high carbon-use efficiency in a seasonally dry pine forest. Global Change Biol. 14, 1553-1567 (2008).

47. Bolstad, P. V., Davis, K. J., Martin, J., Cook, B. D. \& Wang, W. Component and whole-system respiration fluxes in northern deciduous forests. Tree Physiol. 24, 493-504 (2004).

48. Gielen, B. et al. Biometric and eddy covariance-based assessment of decadal carbon sequestration of a temperate Scots pine forest. Agr. Forest Meteorol. 174, 135-143 (2013).

49. Legendre, P. Model II regression user's guide. R edition, Available at https:// cran.r-project.org/web/packages/lmodel2/vignettes/mod2user.pdf (2013).

50. Zeileis, A. Object-oriented computation of sandwich estimators. J. Stat. Softw. 16 (2006); https://www.jstatsoft.org/article/view/v016i09.

51. Hobbie, E. A. Carbon allocation to ectomycorrhizal fungi correlates with belowground allocation in culture studies. Ecology 87, 563-569 (2006).

52. The R Core Team. $R$ : A language and environment for statistical computing (R Foundation for Statistical Computing. https://cran.r-project.org/doc/ manuals/r-release/fullrefman.pdf, (2016).

53. Bain, W. G. et al. Wind-induced error in the measurement of soil respiration using closed dynamic chambers. Agr. Forest Meteorol. 131, 225-232 (2005). 
54. Bloemen, J., McGuire, M. A., Aubrey, D. P., Teskey, R. O. \& Steppe, K. Transport of root-respired $\mathrm{CO}_{2}$ via the transpiration stream affects aboveground carbon assimilation and $\mathrm{CO}_{2}$ efflux in trees. New Phytol. 197, 555-565 (2013).

55. Teskey, R. O. \& McGuire, M. A. Carbon dioxide transport in xylem causes errors in estimation of rates of respiration in stems and branches of trees. Plant Cell Environ. 25, 1571-1577 (2002).

56. Marthews, T. R. et al. Measuring Tropical Forest Carbon Allocation and Cycling: A RAINFOR-GEM Field Manual for Intensive Census Plots (v3.0). Manual (Global Ecosystems Monitoring Network. http://gem.tropicalforests.ox.ac.uk/, 2014).

\section{Acknowledgements}

M.C. and S.V. are Postdoctoral Fellows of the Research Foundation-Flanders (FWO) S.L. is funded by the European Research Council (ERC) Starting Grant 242564 (DOFOCO) and YM by ERC Advanced Investigator Grant 321131 (GEM-TRAIT) and the Jackson Foundation. I.A.J. and J.P. acknowledge the European Research Council Synergy grant ERC-2013-SyG-610028 IMBALANCE-P. We thank Gianluca Tramontana for the DEM data extraction and processing. We greatly appreciate the work of the hundreds of scientists and technicians who produced the BM and EC data compared in this analysis. This work used eddy-covariance data acquired and shared by the FLUXNET community, including these networks: AmeriFlux, AfriFlux, AsiaFlux, CarboAfrica, CarboEuropeIP, CarboItaly, CarboMont, ChinaFlux, Fluxnet-Canada, GreenGrass, ICOS, KoFlux, LBA, NECC, OzFlux-TERN, TCOS-Siberia, and USCCC. The FLUXNET eddy-covariance data processing and harmonization was carried out by the ICOS Ecosystem Thematic Center, AmeriFlux Management Project and Fluxdata project of FLUXNET, with the support of CDIAC, and the OzFlux, ChinaFlux and AsiaFlux offices. In particular, the FLUXNET 2015 data set was used for the following sites-years: CN-Cha (2003), CA-Qfo (2005), FI-Hyy (2003-2006), FR-Hes (1997), US-Syv (2002-2003), AU-Tum (2002-2003), CA-TP2 (2006), US-WCr (2000, 2002-2003).

\section{Author contributions}

M.C., S.V., S.L. and I.A.J. conceived the paper; M.C. performed the analyses; M.C. and Y.M. wrote the text; all authors contributed substantially to discussions and revisions.

\section{Additional information}

Supplementary Information accompanies this paper at http://www.nature.com/ naturecommunications

Competing financial interests: The authors declare no competing financial interests.

Reprints and permission information is available online at http://npg.nature.com/ reprintsandpermissions/

How to cite this article: Campioli, M. et al. Evaluating the convergence between eddy-covariance and biometric methods for assessing carbon budgets of forests. Nat. Commun. 7, 13717 doi: 10.1038/ncomms13717 (2016).

Publisher's note: Springer Nature remains neutral with regard to jurisdictional claims in published maps and institutional affiliations.

(c) (i) This work is licensed under a Creative Commons Attribution 4.0 International License. The images or other third party material in this article are included in the article's Creative Commons license, unless indicated otherwise in the credit line; if the material is not included under the Creative Commons license, users will need to obtain permission from the license holder to reproduce the material. To view a copy of this license, visit http://creativecommons.org/licenses/by/4.0/

C) The Author(s) 2016 